\title{
Mutations in the $S L C 30 A 8$ gene are not a major cause of MODY or other forms of early-onset, autosomal dominant type 2 diabetes
}

\author{
M. Borowiec • R. Thompson - C. Powers - R. Xu • \\ T. Dickey • A. Doria
}

Received: 17 May 2007 / Accepted: 19 June 2007 / Published online: 27 July 2007

(C) Springer-Verlag 2007

Keywords Genetics · Maturity onset diabetes of the young . MODY. Type 2 diabetes

\begin{tabular}{ll}
\multicolumn{2}{l}{ Abbreviations } \\
MAF & minor allele frequency \\
SLC30A8 & solute carrier family 30 member 8 \\
SNP & single nucleotide polymorphism \\
UTR & untranslated region
\end{tabular}

To the Editor: MODY is a relatively rare type of familial diabetes that is characterised by a young age of onset and an autosomal dominant mode of inheritance. The availability of large families with multiple affected members has facilitated genetic studies of this syndrome and this has led to the identification of six distinct MODY genes [1]. Several reports suggest that other MODY genes exist in addition to those identified to date $[1,2]$. In the UK, about $15 \%$ of MODY cases do not seem to result from mutations in known MODY

M. Borowiec $\cdot$ R. Thompson $\cdot$ C. Powers $\cdot$ R. Xu $\cdot$ T. Dickey $\cdot$

A. Doria

Research Division, Joslin Diabetes Center,

Boston, MA, USA

M. Borowiec $\cdot$ R. Xu $\cdot$ A. Doria

Department of Medicine, Harvard Medical School,

Boston, MA, USA

A. Doria $(\bowtie)$

Section on Genetics and Epidemiology, Joslin Diabetes Center, One Joslin Place,

Boston, MA 02215, USA

e-mail: alessandro.doria@joslin.harvard.edu genes [2]. The proportion of unaccounted MODY is even higher if one uses a broader definition of the disease, one that takes into account the fact that MODY is often diagnosed after the traditional age limit of 25 years [1].

The recent identification of common polymorphisms contributing to multifactorial forms of type 2 diabetes [3-6] raises the hypothesis that more severe but less common mutations in the same genes may be responsible for unaccounted MODY cases. Proving this hypothesis would provide further support for a role of these genes in diabetes, and would offer useful monogenic models to study the mechanisms through which dysfunction of these genes cause hyperglycaemia. This would be analogous to other genes such as KCNJ11, PPARG, HNF4A, and GCK, in which mutations cause monogenic diabetes, and common genetic variation is associated with increased susceptibility to type 2 diabetes. Of the recently described genes in which genetic variation plays a role in susceptibility to type 2 diabetes, the gene encoding the zinc transporter solute carrier family 30 member 8 (SLC30A8) is an especially interesting candidate because of its almost exclusive expression in beta cells and the association of an amino acid polymorphism in this gene with forms of type 2 diabetes characterised by a relatively young onset and leanness [3]. While previous genome-wide scans for linkage with MODY have not identified sizable logarithm of odds (LOD) scores in the region of SLC30A8 (8q24) [7, $8]$, mutations in this gene might play a role in selected families.

We investigated whether rare mutations in SLC $30 A 8$ contribute to diabetes in 53 extended kindreds, in which early-onset type 2 diabetes segregated with an autosomal dominant pattern of inheritance and was not due to mutations in known MODY genes. The recruitment of 
these families and the clinical characteristics of 21 of them have been previously described [7]. On average, each family included seven affected individuals and four nondiabetic members. In 45 of these families, the average age at diagnosis of diabetes was 35 years or younger, the average age at diagnosis of the remaining eight families was between 36 and 45 years. The average age of probands was $18.8 \pm 11.7$ years in the first group and $36.6 \pm 8.2$ years in the second. Thirty-three of these families met a strict definition of MODY (i.e. had an autosomal dominant mode of inheritance and at least two affected members with diabetes onset before age 25). Forty-two families were nonHispanic white, six African-American, two Hispanic, one Native American, one Asian, and one originated from the Pacific Islands. The eight exons of SCL30A8, the exonintron boundaries, and 800 and $900 \mathrm{bp}$ of the $5^{\prime}$ and $3^{\prime}$ flanking regions, respectively, were sequenced in each family proband. Included in the screening were also two additional $5^{\prime}$ exons, which were predicted by alignment with ESTs, and $200 \mathrm{bp}$ flanking these exons on the $5^{\prime}$ side.

We identified 31 sequence differences, which are reported in Table 1. Seventeen of these were common polymorphisms that had already been described and had an rs number. These included rs13266634 - the non-synonymous single nucleotide polymorphism (SNP; Arg325Trp) that was found to be associated with type 2 diabetes in genome-wide association studies [3-6]. The genotype distribution of this SNP was not significantly different in diabetic $(n=337)$ and non-diabetic $(n=187)$ family members ( $p=0.41$ according to a general estimating equation model taking into account familial clustering). Another nonsynonymous SNP, also affecting codon 325 (Arg325Gln, rs16889462) was found in a single African-American family, consistent with the fact that this variant is relatively frequent in population of African descent (minor allele frequency [MAF] 0.09-0.12), but is not found in whites. No obvious

Table 1 Sequence differences identified among the probands of 52 families with MODY or early-onset, autosomal dominant type 2 diabetes

\begin{tabular}{|c|c|c|c|c|c|}
\hline Position & Location & Substitution & rs number & Frequency $^{\mathrm{a}}$ & MAF \\
\hline $118,216,255$ & 5' Flanking & $\mathrm{G}>\mathrm{T}$ & - & $0 / 1 / 52$ & 0.0094 \\
\hline $118,216,905$ & Intron 1 & $\mathrm{~T}>\mathrm{G}$ & - & $0 / 2 / 51$ & 0.0189 \\
\hline $118,228,374$ & Exon 2 & $\mathrm{~T}>\mathrm{C}$ (Ser24Ser) & - & $0 / 2 / 51$ & 0.0189 \\
\hline $118,234,330$ & Intron 2 & $\mathrm{~A}>\mathrm{G}$ & rs6469675 & $6 / 18 / 29$ & 0.283 \\
\hline $118,238,899$ & Intron 3 & $\mathrm{G}>\mathrm{A}$ & rs924922 & $6 / 18 / 29$ & 0.283 \\
\hline $118,238,940$ & Intron 3 & $\mathrm{~A}>\mathrm{T}$ & rs6996470 & $2 / 11 / 40$ & 0.142 \\
\hline $118,239,287$ & Intron 4 & $\mathrm{C}>\mathrm{T}$ & - & $0 / 1 / 52$ & 0.0094 \\
\hline $118,244,496$ & Intron 5 & $\mathrm{G}>\mathrm{T}$ & - & $0 / 1 / 52$ & 0.0094 \\
\hline $118,244,840$ & Intron 5 & ins $\mathrm{T}$ & - & $0 / 1 / 52$ & 0.0094 \\
\hline $118,252,732$ & Intron 7 & $\mathrm{~A}>\mathrm{G}$ & rs2464592 & $8 / 18 / 27$ & 0.321 \\
\hline $118,252,768$ & Intron 7 & $\mathrm{G}>\mathrm{A}$ & rs2466299 & $6 / 13 / 34$ & 0.236 \\
\hline $118,253,964$ & Exon 8 & $\mathrm{C}>\mathrm{T}(\operatorname{Arg} 325 \operatorname{Trp})$ & rs 13266634 & $5 / 19 / 29$ & 0.274 \\
\hline $118,253,965$ & Exon 8 & $\mathrm{C}>\mathrm{T}(\operatorname{Arg} 325 \mathrm{Gln})$ & rs 16889462 & $0 / 1 / 52$ & 0.0094 \\
\hline $118,254,206$ & Exon 8 (3' UTR) & $\mathrm{G}>\mathrm{A}$ & rs3802177 & $5 / 19 / 29$ & 0.274 \\
\hline $118,254,222$ & Exon 8 (3' UTR) & $\mathrm{T}>\mathrm{C}$ & rs2466295 & $9 / 21 / 23$ & 0.368 \\
\hline $118,254,244$ & Exon 8 (3' UTR) & $\mathrm{C}>\mathrm{G}$ & rs2466294 & $14 / 23 / 16$ & 0.481 \\
\hline $118,254,489$ & Exon 8 (3' UTR) & $\mathrm{A}>\mathrm{C}$ & - & $0 / 1 / 52$ & 0.0094 \\
\hline $118,254,914$ & Exon 8 (3' UTR) & $\mathrm{A}>\mathrm{G}$ & rs 11558471 & $5 / 20 / 28$ & 0.283 \\
\hline $118,255,119$ & Exon 8 (3' UTR) & $\mathrm{A}>\mathrm{G}$ & rs 2466293 & $7 / 27 / 19$ & 0.387 \\
\hline $118,255,727$ & Exon 8 (3' UTR) & $\mathrm{T}>\mathrm{G}$ & - & $0 / 1 / 52$ & 0.0094 \\
\hline $118,255,876$ & Exon 8 (3' UTR) & $\mathrm{C}>\mathrm{T}$ & - & $0 / 1 / 52$ & 0.0094 \\
\hline $118,255,987$ & Exon 8 (3' UTR) & $\mathrm{C}>\mathrm{G}$ & - & $0 / 8 / 45$ & 0.075 \\
\hline $118,257,007$ & Exon 8 (3' UTR) & $\mathrm{G}>\mathrm{A}$ & rs 10282940 & $1 / 12 / 40$ & 0.132 \\
\hline $118,256,688$ & Exon 8 (3' UTR) & ins $\mathrm{C}$ & - & $0 / 1 / 52$ & 0.0094 \\
\hline $118,257,585$ & Exon 8 (3' UTR) & del CTTA & - & $0 / 3 / 50$ & 0.028 \\
\hline $118,258,463$ & 3' Flanking & $\mathrm{A}>\mathrm{G}$ & - & $0 / 1 / 52$ & 0.0094 \\
\hline $118,258,584$ & 3' Flanking & $\mathrm{C}>\mathrm{T}$ & rs 16889464 & $1 / 10 / 42$ & 0.113 \\
\hline $118,258,682$ & 3' Flanking & $\mathrm{G}>\mathrm{A}$ & rs4289843 & $3 / 12 / 48$ & 0.170 \\
\hline $118,258,712$ & 3' Flanking & $\mathrm{T}>\mathrm{C}$ & rs2466292 & $4 / 16 / 33$ & 0.226 \\
\hline $118,258,747$ & 3' Flanking & $\mathrm{A}>\mathrm{G}$ & rs7813920 & $7 / 15 / 31$ & 0.274 \\
\hline $118,258,881$ & 3' Flanking & $\mathrm{C}>\mathrm{T}$ & - & $0 / 1 / 52$ & 0.0094 \\
\hline
\end{tabular}

${ }^{\text {a }}$ Minor allele homozygotes/heterozygotes/major allele homozygotes 
segregation between this polymorphism and diabetes was observed in this family. Only four of the nine diabetic members were heterozygous, and one of them had received the minor allele from a non-diabetic founder. All other known polymorphisms were placed in introns, $3^{\prime}$ untranslated region (UTR), or $3^{\prime}$ flanking regions, their functions unknown. They were all frequent, with MAF among the probands ranging from $0.11-0.48$.

The 14 remaining sequence differences were relatively rare and had not been described before (Table 1). Ten were observed in one family, two in two families (both of African-American descent), one in three families, and one in eight families. Although none changed amino acid sequence, two had potentially interesting locations. One was a G/T substitution at position $118,216,255$, which was placed in a conserved element $263 \mathrm{bp} 5^{\prime}$ of the SLC30A8 transcription start and disrupted a predicted binding site for liver X receptor/retinoid X receptor (LXR/RXR) heterodimers. The other, placed at position $118,257,585$, consisted of a four nucleotide (CTTA) deletion in the 3' UTR, potentially affecting mRNA stability. However, neither substitution showed obvious segregation with diabetes in these families. The G/T substitution at position 118,216,255 entered the family through a non-diabetic founder and was not carried by any diabetic members other than the proband. All three affected members of one of the families with the CTTA deletion carried the variant. However, only a minority of the affected members of the other two families in which the deletion was observed were carriers. Similar patterns, consistent with a lack of segregation with diabetes, were observed for the other mutations.

Taken together, these data suggest that rare mutations in SLC 30A8 are unlikely to be responsible for cases of MODY or early-onset, autosomal dominant type 2 diabetes unaccounted for by the six known MODY genes, although we cannot exclude a role of mutations in as yet unidentified regulatory elements, or in other family collections. This contrasts with the case of common multifactorial forms of type 2 diabetes, for which an association with a common SLC30A8 polymorphism has been consistently documented [3-6]. Such discrepancy is similar to that observed by
Cauchi et al. for TCF7L2 - another gene involved in type 2 diabetes susceptibility, mostly through an effect on beta cell function [9]. These findings highlight the high degree of genetic heterogeneity of type 2 diabetes and highlight the need to study several subtypes of this disease to comprehensively identify all the different pathways that are involved in the modulation of glucose metabolism.

Acknowledgement This research was supported by National Institutes of Health grants DK55523 and DK36836 (Genetics Core of the Diabetes and Endocrinology Research Center at the Joslin Diabetes Center).

Duality of interest The authors declare that there is no duality of interest associated with this manuscript.

\section{References}

1. Doria A, Plengvidhya N (2000) Recent advances in the genetics of maturity onset diabetes of the young and other forms of autosomal dominant diabetes. Curr Opin Endocrinol Diabetes 7:203-210

2. Frayling TM, Evans JC, Bulman MP et al (2001) Beta-cell genes and diabetes: molecular and clinical characterization of mutations in transcription factors. Diabetes 50(Suppl 1):S94-S100

3. Sladek R, Rocheleau G, Rung J et al (2007) A genome-wide association study identifies novel risk loci for type 2 diabetes. Nature 445:881-885

4. Zeggini E, Weedon MN, Lindgren CM et al (2007) Replication of genome-wide association signals in UK. Samples reveals risk loci for type 2 diabetes. Science 316:1336-1341

5. Scott LJ, Mohlke KL, Bonnycastle LL et al (2007) A genome-wide association study of type 2 diabetes in Finns detects multiple susceptibility variants. Science 316:1341-1345

6. Saxena R, Voight BF, Lyssenko V et al (2007) Genome-wide association analysis identifies loci for type 2 diabetes and triglyceride levels. Science 316:1331-1336

7. Kim SH, Ma X, Weremowicz S et al (2004) Identification of a locus for maturity-onset diabetes of the young (MODY) on chromosome 8p23. Diabetes 53:1375-1380

8. Frayling TM, Lindgren CM, Chevre JC et al (2003) A genomewide scan in families with maturity-onset diabetes of the young: evidence for further genetic heterogeneity. Diabetes 52:872-881

9. Cauchi S, Vaxillaire M, Choquet $\mathrm{H}$ et al (2007) No major contribution of TCF7L2 sequence variants to maturity onset of diabetes of the young (MODY) or neonatal diabetes mellitus in French white subjects. Diabetologia 50:214-216 